\title{
Prognosis of Early-stage Part-solid and Pure-solid Lung Adenocarcinomas
}

\author{
FUMIHIKO KINOSHITA ${ }^{1}$, GOUJI TOYOKAWA ${ }^{1}$, TAICHI MATSUBARA ${ }^{1}$, \\ YUKA KOZUMA $^{1}$, NAOKI HARATAKE ${ }^{1}$, SHINKICHI TAKAMORI ${ }^{1}$, TAKAKI AKAMINE ${ }^{1}$, \\ FUMIHIKO HIRAI ${ }^{1}$, TOMOYOSHI TAKENAKA ${ }^{2}$, TETSUZO TAGAWA ${ }^{1}$ and YOSHIHIKO MAEHARA ${ }^{1}$ \\ ${ }^{1}$ Department of Surgery and Science, Graduate School of Medical Sciences, Kyushu University, Fukuoka, Japan; \\ ${ }^{2}$ Department of Surgery, Hiroshima Red Cross Hospital and Atomic Bomb Survivors Hospital, Hiroshima, Japan
}

\begin{abstract}
Background/Aim: In the new TNM classification (8th edition) of lung cancer, T category is defined based on the solid component size; therefore, part solid type (PST) with and solid type (ST) without ground glass opacity (GGO) are categorized as same $T$ value according to their solid component sizes. However, differences between these tumors have not been clarified. Patients and Methods The study included 274 pStage I lung adenocarcinoma patients who had undergone surgery at our Institution from 2003 to 2012. Their tumors were classified as pure GGO, PST, and ST. After propensity score matching for solid component size, we compared prognoses between PST and ST. Results: The same percentage was noted for PST and ST tumors (119/274; 43.4\%). After propensity score matching, the disease-free survival (DFS) was significantly worse in ST than PST (5-year DFS: $69.2 \%$ versus $88.7 \%$; $p=0.0241$ ). Conclusion: Prognoses of PST and ST adenocarcinomas differ even when their solid component sizes are the same.
\end{abstract}

The TNM classification of lung cancer was revised in January 2017 (8th edition) (1). In this version, the T category was subdivided into $1 \mathrm{~cm}$ increments and was defined by the size of the solid component, excluding ground glass opacity (GGO).

In lung adenocarcinomas, radiological GGO is associated with histologically non-invasive or minimally invasive characteristics (2), while higher ratios of solid component to total tumor diameter (consolidation/tumor; $\mathrm{C} / \mathrm{T}$ ratio) are

Correspondence to: Tetsuzo Tagawa, MD, Ph.D., Department of Surgery and Science, Graduate School of Medical Sciences, Kyushu University, 311 Maidashi, Higashi-ku, 812-8582 Fukuoka, Japan. Tel: +81926425466, Fax: +81926425482, e-mail: t_tagawa@ surg2.med.kyushu-u.ac.jp

Key Words: Lung adenocarcinoma, TNM classification, propensity score matching. reportedly associated with histological evidence of invasiveness (3). Because solid component size is a better prognostic factor than whole tumor size in Stage IA lung adenocarcinomas (4), the TNM classification was revised mainly according to the size of the solid component of the tumor. Thus, part solid type (PST) with GGO and solid type (ST) without GGO are categorized as of the same T category when their solid components are the same size (Figure 1).

However, differences in clinicopathological characteristics and prognoses between PST and ST have not been fully investigated. Although it has been shown by propensity score matching that prognoses of PST and ST were similar for Stage IA non-small cell lung cancer (5), other studies revealed differences in clinicopathological characteristics and prognoses between PST and ST (6-8). Therefore, in the present study we investigated whether the clinicopathological characteristics and prognoses of PST and ST tumors are the same or not. We used propensity score matching to investigate differences in clinicopathological characteristics and prognoses between patients with pathological Stage I PST versus ST lung adenocarcinoma who had undergone surgery.

\section{Patients and Methods}

Patients. This retrospective study included a cohort of 274 patients with pathological Stage I (7th TNM classification) primary lung adenocarcinoma who had undergone surgery between January 2003 and December 2012 at the Department of Surgery and Science, Graduate School of Medical Sciences, Kyushu University. After surgery, routine follow-up, including physical examination, blood tests (including serum tumor markers), and chest radiographs was performed at 3 month intervals for the first 3 years, and 6 monthly thereafter. The patients were divided into the following three groups, according to the tumor $\mathrm{C} / \mathrm{T}$ ratios as estimated on computed tomography (CT) images obtained within one month before surgery: pure GGO type $(\mathrm{C} / \mathrm{T}=0)$, PST $(0<\mathrm{C} / \mathrm{T}<1)$, and ST $(\mathrm{C} / \mathrm{T}=1)$. Clinicopathological characteristics, disease-free survival (DFS), and overall survival (OS) were retrospectively analyzed in the PST and ST subgroups. Clinicopathological characteristics 

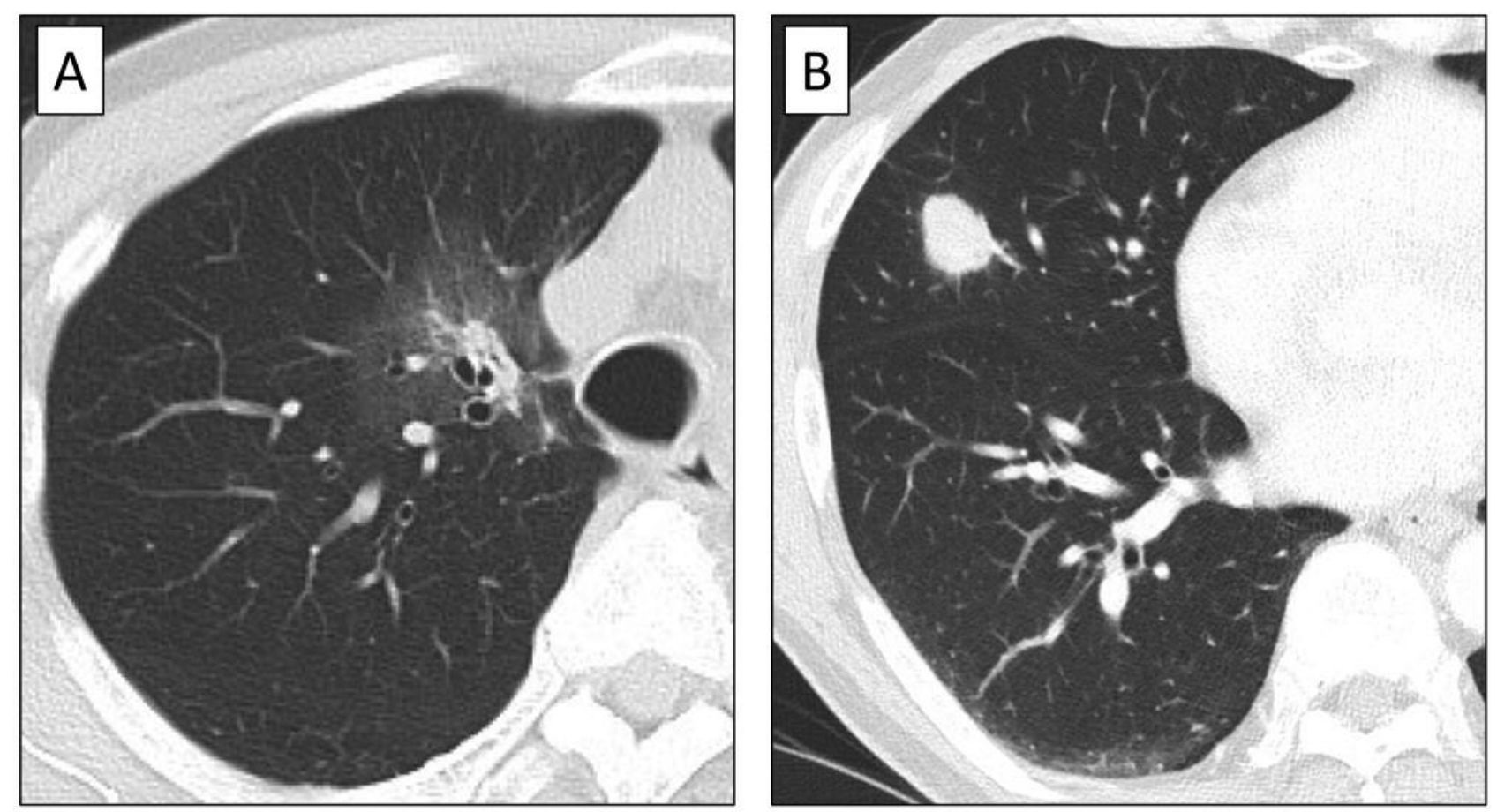

Figure 1. Computed tomography images of part solid type tumor $(A)$ and solid type tumor $(B)$.

assessed included age, sex, smoking (pack year index), radiological tumor size, radiological solid component size, maximum standardized uptake value (SUV-max), pleural invasion $(\mathrm{pl})$, lymphatic invasion (ly), vascular invasion (v), predominant histological component, epidermal growth factor receptor (EGFR) mutation, and programmed cell death ligand-1 (PD-L1) expression. EGFR mutation had been assessed in tumor tissue using the peptide nucleic acid-locked nucleic acid polymerase chain reaction clamp method (LSI Medience Corporation, Tokyo, Japan). PD-L1 expression had been investigated by immunohistochemical staining with antibody against PD-L1 (rabbit monoclonal, clone SP142, Spring Bioscience, Ventana, Tucson, AZ, USA) as described previously (9). In the present study, more than 5\% tumor membrane staining was considered as positive PD-L1 staining (10).

Statistical analysis. Fisher's exact test was used to analyze patient characteristics. DFS was defined as the period between surgery and the date of the last follow-up, recurrence or death, and OS as the period between surgery and the date of last follow-up or death. Survival curves were estimated by using the Kaplan-Meier method with the log-rank test. All results were considered statistically significant at $p<0.05$. JMP pro 13.0 software (SAS Institute, Cary, $\mathrm{NC}, \mathrm{USA}$ ) was used for all statistical analyses.

Propensity score matching. Propensity score matching for solid component size was performed to eliminate differences in solid component size. A propensity score difference of 0.05 was adopted as the maximum caliper width for matching PST and ST groups. After propensity score matching, 48 matched patients per group were included in the analysis.

\section{Results}

Patient characteristics. The study cohort comprised 276 patients with Stage I lung adenocarcinoma who had undergone surgical resection (Table I). Thirty-six (13.1\%), $119(43.4 \%)$, and 119 patients (43.4\%) were classified as having pure GGO, PST, and ST adenocarcinomas, respectively. The median age was 69 years (range=34-85), and 134 patients $(48.6 \%)$ were men. The radiological median size of total tumor and solid component were $19.2 \mathrm{~mm}$ (range=2.7-106.5) and $12.6 \mathrm{~mm} \quad$ (range=0.0-70.3), respectively. As to surgical procedures, bilobectomy, lobectomy, segmentectomy, and partial resection were performed on $2(0.7 \%), 183(66.8 \%), 35(12.8 \%)$, and 54 patients $(19.7 \%)$, respectively. On histological examination of resected tumors, 55 patients $(20.1 \%)$ had tumors of lepidic pattern [adenocarcinoma in situ (AIS), minimally invasive adenocarcinoma (MIS), or lepidic adenocarcinoma] and 219 invasive adenocarcinomas $(79.9 \%)$. The clinicopathological characteristics according to study group before propensity score matching are shown in Table II. There were significant differences between the PST and ST groups in radiological solid size $(p<0.0001)$, SUV-max $(p<0.0001)$, pl $(p<0.0001)$, ly $(p=0.0031), \mathrm{v} \quad(p<0.0001)$, predominant histological component $(p<0.0001)$, presence of EGFR mutation $(p<0.0001)$, and PD-L1 expression $(p=0.0013)$. After 
Table I. Clinicopathological characteristics of patients with resected pathological Stage I (according to 7th TNM classification) adenocarcinoma.

\begin{tabular}{|c|c|}
\hline Characteristic & $\mathrm{N}=274$ \\
\hline \multicolumn{2}{|l|}{ Age (years) } \\
\hline Median & 69 \\
\hline Range & $34-85$ \\
\hline \multicolumn{2}{|l|}{ Gender } \\
\hline Male & $134(48.9 \%)$ \\
\hline Female & $140(51.1 \%)$ \\
\hline \multicolumn{2}{|c|}{ Smoking (pack year index) } \\
\hline$<30$ & $188(68.6 \%)$ \\
\hline$\geq 30$ & $86(31.4 \%)$ \\
\hline \multicolumn{2}{|c|}{ Radiological tumor type } \\
\hline Pure GGO & $36(13.1 \%)$ \\
\hline Part solid & $119(43.4 \%)$ \\
\hline Pure solid & $119(43.4 \%)$ \\
\hline \multicolumn{2}{|c|}{ Radiological size of solid component (mm) } \\
\hline Median & 12.2 \\
\hline Range & $0.0-47.5$ \\
\hline \multicolumn{2}{|c|}{ Radiological tumor size (mm) } \\
\hline Median & 19.0 \\
\hline Range & $2.7-48.7$ \\
\hline \multicolumn{2}{|l|}{ SUV-max* } \\
\hline$<2.5$ & $84(51.2 \%)$ \\
\hline$\geq 2.5$ & $80(48.8 \%)$ \\
\hline \multicolumn{2}{|l|}{ Surgical procedure } \\
\hline Bilobectomy & $2(0.7 \%)$ \\
\hline Lobectomy & $183(66.8 \%)$ \\
\hline Segmentectomy & $35(12.8 \%)$ \\
\hline Partial resection & $54(19.7 \%)$ \\
\hline \multicolumn{2}{|l|}{$\mathrm{pl} *$} \\
\hline Negative & $240(87.9 \%)$ \\
\hline Positive & $33(12.1 \%)$ \\
\hline \multicolumn{2}{|l|}{ ly } \\
\hline Negative & $255(93.1 \%)$ \\
\hline Positive & $19(6.9 \%)$ \\
\hline \multicolumn{2}{|l|}{$\mathrm{v}$} \\
\hline Negative & $227(82.8 \%)$ \\
\hline Positive & $47(17.2 \%)$ \\
\hline \multicolumn{2}{|c|}{ Predominant histological component } \\
\hline AIS & $34(12.4 \%)$ \\
\hline MIA & $1(0.4 \%)$ \\
\hline Lepidic & $20(7.3 \%)$ \\
\hline Papillary & $197(71.9 \%)$ \\
\hline Acinar & $3(1.1 \%)$ \\
\hline Micropapillary & $1(0.4 \%)$ \\
\hline Solid & $14(5.1 \%)$ \\
\hline Variants & $4(1.5 \%)$ \\
\hline \multicolumn{2}{|l|}{ EGFR mutation* } \\
\hline Negative & $89(52.0 \%)$ \\
\hline Positive & $82(48.0 \%)$ \\
\hline \multicolumn{2}{|l|}{ PD-L1 expression } \\
\hline$<5 \%$ & $227(82.8 \%)$ \\
\hline$\geq 5 \%$ & $47(17.2 \%)$ \\
\hline
\end{tabular}

*Available data were counted, excluding unknown data. AIS, Adenocarcinoma in situ; EGFR, epidermal growth factor receptor; GGO, ground glass opacity; ly, lymphatic invasion; MIA, minimally-invasive adenocarcinoma; PD-L1, programmed cell death ligand-1; pl, pleural invasion; SUV, maximum standardized uptake value; v, vascular invasion.
Table II. Clinicopathological characteristics of patients according to adenocarcinoma type.

\begin{tabular}{|c|c|c|c|}
\hline Characteristics & $\begin{array}{l}\text { Part solid } \\
\text { (119) }\end{array}$ & $\begin{array}{l}\text { Pure solid } \\
\text { (119) }\end{array}$ & $p$-Value \\
\hline Age (years) & & & 0.6456 \\
\hline Median & 69 & 68 & \\
\hline Range & $34-84$ & $37-85$ & \\
\hline Gender & & & 0.1537 \\
\hline Male & $54(45.4 \%)$ & $66(55.5 \%)$ & \\
\hline Female & $65(54.6 \%)$ & $53(44.5 \%)$ & \\
\hline Smoking (pack year index) & & & 0.1587 \\
\hline$<30$ & $89(74.8 \%)$ & $69(58.0 \%)$ & \\
\hline$\geq 30$ & $30(25.2 \%)$ & $50(42.0 \%)$ & \\
\hline Radiological tumor & & & \\
\hline $\begin{array}{l}\text { size }(\mathrm{mm}) \\
\text { Median }\end{array}$ & 18.9 & 20.9 & 0.2687 \\
\hline Range & $6.5-48.7$ & $2.7-47.5$ & \\
\hline $\begin{array}{l}\text { Radiological solid } \\
\text { size }(\mathrm{mm})\end{array}$ & & & $<0.0001$ \\
\hline Median & 9.2 & 20.9 & \\
\hline Range & $1.9-36.7$ & $2.7-47.5$ & \\
\hline SUV-max* & & & $<0.0001$ \\
\hline$<2.5$ & $58(70.7 \%)$ & $14(20.0 \%)$ & \\
\hline$\geq 2.5$ & $24(29.3 \%)$ & $56(80.0 \%)$ & \\
\hline Surgical procedures & & & 0.0279 \\
\hline Bilobectomy & $1(0.8 \%)$ & $1(0.8 \%)$ & \\
\hline Lobectomy & $81(68.1 \%)$ & $89(74.8 \%)$ & \\
\hline Segmentectomy & $7(5.9 \%)$ & $15(12.6 \%)$ & \\
\hline Partial resection & $30(25.2 \%)$ & $14(11.7 \%)$ & \\
\hline $\mathrm{pl}^{*}$ & & & $<0.0001$ \\
\hline Negative & $118(99.2 \%)$ & $88(74.6 \%)$ & \\
\hline Positive & $1(0.8 \%)$ & $30(25.4 \%)$ & \\
\hline ly & & & 0.0031 \\
\hline Negative & $116(97.5 \%)$ & $103(86.5 \%)$ & \\
\hline Positive & $3(2.5 \%)$ & $16(13.5 \%)$ & \\
\hline $\mathrm{v}$ & & & $<0.0001$ \\
\hline Negative & $111(93.3 \%)$ & $82(68.9 \%)$ & \\
\hline Positive & $8(6.7 \%)$ & $37(31.1 \%)$ & \\
\hline $\begin{array}{l}\text { Predominant histological } \\
\text { component }\end{array}$ & & & $<0.0001$ \\
\hline AIS & $19(16.0 \%)$ & $3(2.5 \%)$ & \\
\hline MIA & $1(0.8 \%)$ & $0(0.0 \%)$ & \\
\hline Lepidic & $13(10.9 \%)$ & $2(1.7 \%)$ & \\
\hline Papillary & $83(69.8 \%)$ & $95(79.8 \%)$ & \\
\hline Acinar & $3(2.5 \%)$ & $0(0.0 \%)$ & \\
\hline Micropapillary & $0(0.0 \%)$ & $1(0.8 \%)$ & \\
\hline Solid & $0(0.0 \%)$ & $14(11.8 \%)$ & \\
\hline Variants & $0(0.0 \%)$ & $4(3.3 \%)$ & \\
\hline EGFR mutation* & & & $<0.0001$ \\
\hline Negative & $36(40.9 \%)$ & $48(75.0 \%)$ & \\
\hline Positive & $52(59.1 \%)$ & $16(25.0 \%)$ & \\
\hline PD-L1 expression* & & & 0.0013 \\
\hline$<5 \%$ & $107(89.9 \%)$ & $87(73.1 \%)$ & \\
\hline$\geq 5 \%$ & $12(10.1 \%)$ & $32(26.9 \%)$ & \\
\hline
\end{tabular}

*Available data were counted, excluding unknown data. AIS, Adenocarcinoma in situ; EGFR, epidermal growth factor receptor; GGO, ground glass opacity; ly, lymphatic invasion; MIA, minimallyinvasive adenocarcinoma; PD-L1, programmed cell death ligand-1; pl, pleural invasion; SUV, maximum standardized uptake value; v, vascular invasion. 
Table III. Clinicopathological characteristics of part and pure solid adenocarcinomas after propensity score matching for size of solid component.

\begin{tabular}{|c|c|c|c|}
\hline Characteristics & $\begin{array}{l}\text { Part solid } \\
\quad(\mathrm{n}=48)\end{array}$ & $\begin{array}{l}\text { Pure solid } \\
\quad(\mathrm{n}=48)\end{array}$ & $p$-Value \\
\hline Age (years) & & & 0.2415 \\
\hline Median & 71 & 68 & \\
\hline Range & $45-84$ & $38-85$ & \\
\hline Gender & & & 0.3058 \\
\hline Male & $23(47.9 \%)$ & $29(60.4 \%)$ & \\
\hline Female & $25(52.1 \%)$ & $19(39.6 \%)$ & \\
\hline Smoking (pack year index) & & & 0.0094 \\
\hline$<30$ & $38(79.2 \%)$ & $25(52.1 \%)$ & \\
\hline$\geq 30$ & $10(20.8 \%)$ & $23(47.9 \%)$ & \\
\hline Radiological tumor & & & \\
\hline size $(\mathrm{mm})$ & & & $<0.0001$ \\
\hline Median & 24.6 & 14.2 & \\
\hline Range & $10.7-48.7$ & $2.7-36.5$ & \\
\hline $\begin{array}{l}\text { Radiological size of solid } \\
\text { component }(\mathrm{mm})\end{array}$ & & & 0.9766 \\
\hline Median & 13.9 & 14.2 & \\
\hline Range & $2.4-36.7$ & $2.7-36.5$ & \\
\hline SUV-max* & & & 0.2081 \\
\hline$<2.5$ & $18(56.3 \%)$ & $11(39.3 \%)$ & \\
\hline$\geq 2.5$ & $14(43.7 \%)$ & $17(60.7 \%)$ & \\
\hline Surgical procedure & & & 0.1456 \\
\hline Bilobectomy & $0(0.0 \%)$ & $0(0.0 \%)$ & \\
\hline Lobectomy & $40(83.3 \%)$ & $32(66.7 \%)$ & \\
\hline Segmentectomy & $3(6.3 \%)$ & $8(16.7 \%)$ & \\
\hline Partial resection & $5(10.4 \%)$ & $8(16.7 \%)$ & \\
\hline $\mathrm{pl}^{*}$ & & & 0.0008 \\
\hline Negative & $47(97.9 \%)$ & $35(74.5 \%)$ & \\
\hline Positive & $1(2.1 \%)$ & $12(25.5 \%)$ & \\
\hline ly & & & 0.1112 \\
\hline Negative & $47(97.9 \%)$ & $42(87.5 \%)$ & \\
\hline Positive & $1(2.1 \%)$ & $6(12.5 \%)$ & \\
\hline $\mathrm{v}$ & & & 0.2083 \\
\hline Negative & $41(85.4 \%)$ & $35(72.9 \%)$ & \\
\hline Positive & $7(14.6 \%)$ & $13(27.1 \%)$ & \\
\hline $\begin{array}{l}\text { Predominant histological } \\
\text { component }\end{array}$ & & & 0.0373 \\
\hline AIS & $2(4.2 \%)$ & $1(2.1 \%)$ & \\
\hline MIA & $0(0.0 \%)$ & $0(0.0 \%)$ & \\
\hline Lepidic & $4(8.3 \%)$ & $0(0.0 \%)$ & \\
\hline Papillary & $41(85.4 \%)$ & $39(81.3 \%)$ & \\
\hline Acinar & $1(2.1 \%)$ & $0(0.0 \%)$ & \\
\hline Micropapillary & $0(0.0 \%)$ & $1(2.1 \%)$ & \\
\hline Solid & $0(0.0 \%)$ & $5(10.4 \%)$ & \\
\hline Variants & $0(0.0 \%)$ & $2(2.1 \%)$ & \\
\hline EGFR mutation* & & & 0.0148 \\
\hline Negative & $13(41.9 \%)$ & $19(76.0 \%)$ & \\
\hline Positive & $18(58.1 \%)$ & $6(24.0 \%)$ & \\
\hline PD-L1 expression & & & 0.2243 \\
\hline$<5 \%$ & $40(83.3 \%)$ & $34(70.8 \%)$ & \\
\hline$\geq 5 \%$ & $8(16.7 \%)$ & $14(29.2 \%)$ & \\
\hline
\end{tabular}

*Available data were counted, excluding unknown data. AIS, Adenocarcinoma in situ; EGFR, epidermal growth factor receptor; ly, lymphatic invasion; MIA, minimally-invasive adenocarcinoma; PD-L1, programmed cell death ligand-1; pl, pleural invasion; SUV-max, maximum standardized uptake value; v, vascular invasion.

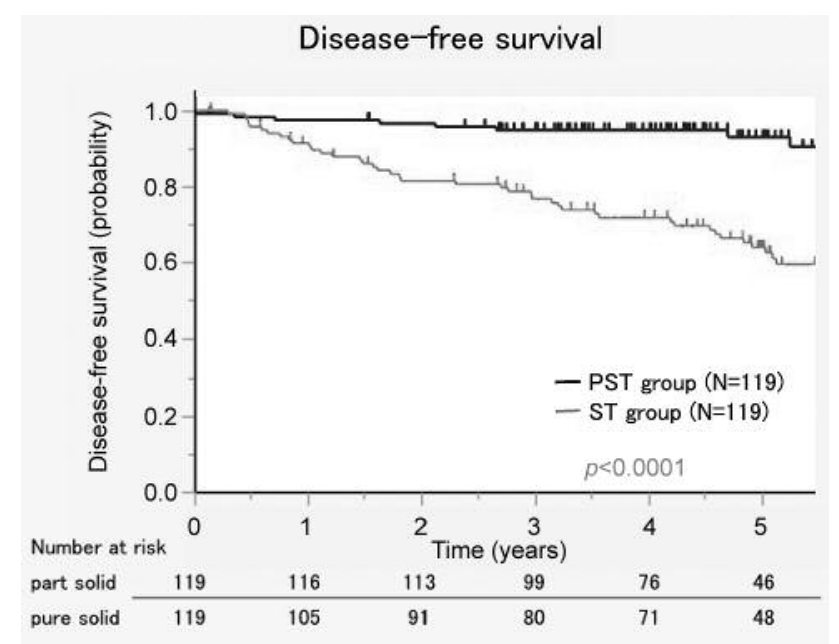

Figure 2. Disease-free survival of part solid type (PST) and solid type (ST) groups before propensity score matching for solid component size showing that the prognosis is worse for the ST than PST group (5 year DFS: $64.1 \%$ versus $93.0 \%$; $p<0.0001)$.

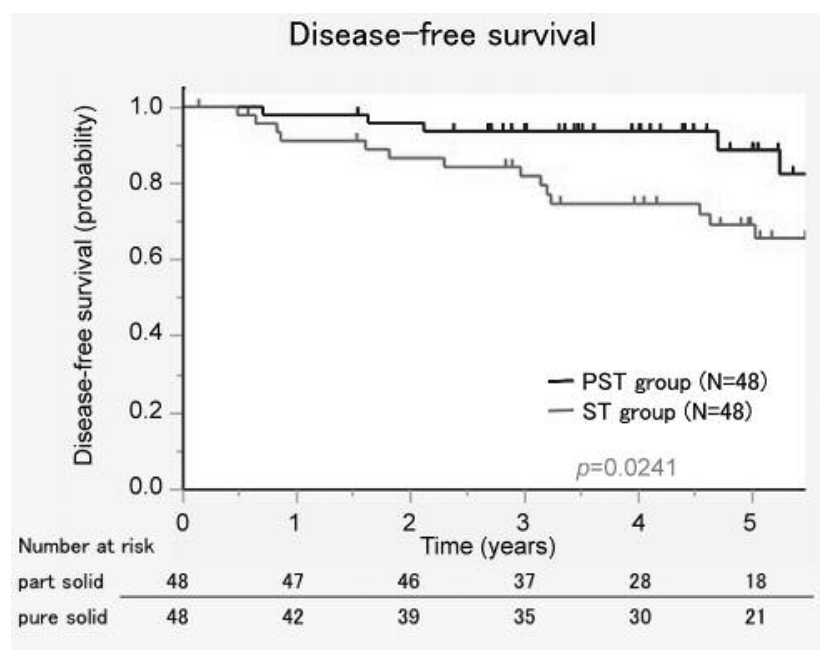

Figure 3. Disease-free survival of part solid type (PST) and solid type (ST) groups after propensity score matching for solid component size shows that that the prognosis of ST group is worse than that of the PST group, even when their solid component sizes are the same (5 year DFS: $69.2 \%$ versus $88.7 \%$; $p=0.0241$ ).

propensity score matching for radiological size of the solid component, smoking history $(p=0.0094), \mathrm{pl}$ positivity ( $p=0.0008)$, and $E G F R$ mutation negativity $(p=0.0148)$ were found to occur more frequently in the ST than PST group (Table III). In addition, the frequency of lepidic pattern (AIS, MIA, and lepidic adenocarcinoma) was higher in the PST than ST group (14.3\% versus $2.1 \%$; $p=0.0373$ ). 
Postoperative survival. The DFS was significantly worse in the ST than the PST group (5-year DFS: $64.1 \%$ versus $93.0 \% ; p<0.0001$; Figure 2); the OS was also worse in the ST than PST group (5-year OS: $86.2 \%$ versus $93.6 \%$; $p=0.0193$ ). Additionally, 5-year DFS and OS were both $97.2 \%$ in the GGO group. Even after propensity score matching for the size of the solid component, the DFS was significantly worse in the ST than the PST group (5-year DFS: $69.2 \%$ versus $88.7 \%$; $p=0.0329$; Figure 3 ). However, there was no significant difference between the PST and ST groups in OS (5-year OS: $88.4 \%$ versus $90.8 \%$; $p=0.6468$ ).

\section{Discussion}

In the present study, we demonstrated a difference in clinicopathological characteristics and prognoses between PST and ST by using propensity score matching in patients with Stage I lung adenocarcinoma. To more accurately determine any discrepancies between PST and ST, the only clinicopathological characteristic matched in propensity score matching was radiological size of solid component. After propensity score matching for solid component size, the DFS was still significantly worse in the ST than PST group. As to clinicopathological characteristics, smoking history, pl positivity, EGFR mutation negativity, and invasive predominance were more frequent in the ST than PST group after propensity score matching for solid component size. Taken together, these differences indicate that the prognosis is worse for patients with ST than PST lung adenocarcinomas.

The relationship between radiological GGO and pathological non-invasiveness in lung adenocarcinoma has recently been receiving increased attention, as indicated by the changes in the 8th TNM classification. The JCOG0804 study showed that curative limited resection for lung adenocarcinoma with tumor diameter $<2 \mathrm{~cm}$ and $\mathrm{C} / \mathrm{T}$ ratio $<0.25$ is not inferior to lobectomy (11). Therefore, it is reasonable to prioritize solid component size over whole tumor diameter including GGO. However, the changes in the 8th TNM classification may lead to confusion since differences in clinicopathological characteristics and prognoses between ST and PST tumors have not been fully investigated. According to the 8th TNM classification, ST and PST tumors are equally treated according to the sizes of their solid components.

A previous study that incorporated propensity score matching revealed the validity of treating PST and ST tumors equally according to the sizes of their solid components (5). However, another study in patients with stage IA lung carcinoma showed that SUV-max was higher for ST than PST tumors and that the DFS of patients with ST tumor was worse than that of those with PST tumors (6). Furthermore, even when the GGO component of a PST tumor is small $(0.75 \leq \mathrm{C} / \mathrm{T}$ ratio $<1)$, the DFS of patients with PST tumors is better than that of those with ST tumors (7).
In early stage non-small cell lung cancer, both DFS and OS of ST tumors are reportedly worse than those of PST tumors in the same clinical $\mathrm{T}$ category (8). By considering these evidences, we suggest that the 8th TNM classification can be further improved.

Biologically, there are two pathways for progression of lung adenocarcinoma: linear and non-linear (12). In linear progression, a premalignant lesion, known as atypical adenomatous hyperplasia, progresses to a pre-invasive adenocarcinoma in situ, which is followed by invasive adenocarcinoma (12). Linear progression is common in women and non-smokers and is associated with genetic changes such as v-Ki-ras2 Kirsten rat sarcoma viral oncogene homolog or EGFR mutation (12). In contrast, non-linear progression refers to a de novo pathway in which malignant change is not preceded clinically and pathologically by a premalignant or preinvasive lesion (12); details of this type of pathogenesis remain unclear. In the current study, the pack year index was lower and the frequency of EGFR mutation higher in the PST than ST group. These findings suggest that non-linear and linear progression may be related to differences between PST and ST tumors. This possible difference in the pathogenesis of PST and ST tumors may, at least in part, explain the results obtained in this study.

One limitation of our study is that the study cohort was relatively small to allow use of univariate and multivariate analysis. Furthermore, the design of this study was retrospective. We consider that the large-scale prospective studies are warranted to further elucidate the difference of the clinicopathological characteristics and prognoses between PST and ST tumors.

In conclusion, the clinicopathological characteristics and prognoses of PST and ST tumors may differ despite the fact that the sizes of their solid component are the same. Further research could elucidate the impact of GGO on lung cancer prognosis and contribute to the selection of the most appropriate treatment.

\section{Acknowledgements}

We thank Dr Trish Reynolds, MBBS, FRACP, from Edanz Group (www.edanzediting.com/ac) for editing a draft of this manuscript.

\section{Authors' Contributions}

FK, GT and TT designed the study. FK and GT wrote the manuscript. TM, YK, TH, ST, TA and FH contributed to data collection and interpretation, and critically reviewed the manuscript. TT and YM performed total organization of writing the manuscript. All authors read and approved the final manuscript.

\section{Conflicts of Interest}

The Authors have no conflicts of interest to declare. 


\section{References}

1 Goldstraw P, Chansky K, Crowley J, Rami-Porta R, Asamura H, Eberhardt WE, Nicholson AG, Groome P, Mitchell A, Bolejack V, International Association for the Study of Lung Cancer S, Prognostic Factors Committee AB, Participating I, International Association for the Study of Lung Cancer S, Prognostic Factors Committee Advisory B and Participating I: The IASLC lung cancer staging project: Proposals for revision of the TNM stage groupings in the forthcoming (Eighth) edition of the TNM classification for lung cancer. J Thorac Oncol 11: 39-51, 2016. PMID: 26762738. DOI: 10.1016/j.jtho.2015.09.009

2 Suzuki K, Koike T, Asakawa T, Kusumoto M, Asamura H, Nagai K, Tada H, Mitsudomi T, Tsuboi M, Shibata T, Fukuda $\mathrm{H}$ and Kato $\mathrm{H}$ : A prospective radiological study of thin-section computed tomography to predict pathological noninvasiveness in peripheral clinical IA lung cancer (Japan Clinical Oncology Group 0201). J Thorac Oncol 6: 751-756, 2011. PMID: 21325976. DOI: $10.1097 /$ JTO.0b013e31821038ab

3 Ohde Y, Nagai K, Yoshida J, Nishimura M, Takahashi K, Suzuki $\mathrm{K}$, Takamochi K, Yokose T and Nishiwaki Y: The proportion of consolidation to ground-glass opacity on high resolution CT is a good predictor for distinguishing the population of noninvasive peripheral adenocarcinoma. Lung cancer 42: 303-310, 2003. PMID: 14644518

4 Asamura H, Hishida T, Suzuki K, Koike T, Nakamura K, Kusumoto M, Nagai K, Tada H, Mitsudomi T, Tsuboi M, Shibata T, Fukuda H and Japan Clinical Oncology Group Lung Cancer Surgical Study G: Radiographically determined noninvasive adenocarcinoma of the lung: survival outcomes of Japan Clinical Oncology Group 0201. J Thorac Cardiovasc Surg 146: 24-30, 2013. PMID: 23398645. DOI: 10.1016/j.jtcvs.2012.12.047

5 Takenaka T, Yamazaki K, Miura N and Takeo S: Prognostic ability of new T1 descriptors in the tumour, node and metastasis classification of surgically treated non-small-cell lung cancer. Interact Cardiovasc Thorac Surg 27: 714-719, 2018. PMID: 29788086. DOI: 10.1093/icvts/ivy 164

6 Tsutani Y, Miyata Y, Yamanaka T, Nakayama H, Okumura S, Adachi S, Yoshimura $\mathrm{M}$ and Okada M: Solid tumors versus mixed tumors with a ground-glass opacity component in patients with clinical stage IA lung adenocarcinoma: Prognostic comparison using high-resolution computed tomography findings. J Thorac Cardiovasc Surg 146: 17-23, 2013. PMID: 23246051. DOI: 10.1016/j.jtcvs.2012.11.019
7 Berry MF, Gao R, Kunder CA, Backhus L, Khuong A, Kadoch M, Leung A and Shrager J: Presence of even a small groundglass component in lung adenocarcinoma predicts better survival. Clin Lung Cancer 19: e47-e51, 2018. PMID: 28743420. DOI: 10.1016/j.cllc.2017.06.020

8 Hattori A, Matsunaga T, Takamochi K, Oh S and Suzuki K: Prognostic impact of a ground glass opacity component in the clinical $\mathrm{T}$ classification of non-small cell lung cancer. J Thorac Cardiovasc Surg 154: 2102-2110, 2017. PMID: 28947198. DOI: $10.1016 / j . j t c v s .2017 .08 .037$

9 Takada K, Okamoto T, Shoji F, Shimokawa M, Akamine T, Takamori S, Katsura M, Suzuki Y, Fujishita T, Toyokawa G, Morodomi Y, Okano S, Oda Y and Maehara Y: Clinical significance of PD-L1 protein expression in surgically resected primary lung adenocarcinoma. J Thorac Oncol 11: 1879-1890, 2016. PMID: 27346415. DOI: 10.1016/j.jtho.2016.06.006

10 Herbst RS, Soria JC, Kowanetz M, Fine GD, Hamid O, Gordon MS, Sosman JA, McDermott DF, Powderly JD, Gettinger SN, Kohrt HE, Horn L, Lawrence DP, Rost S, Leabman M, Xiao Y, Mokatrin A, Koeppen H, Hegde PS, Mellman I, Chen DS and Hodi FS: Predictive correlates of response to the anti-PD-L1 antibody MPDL3280A in cancer patients. Nature 515: 563-567, 2014. PMID: 25428504. DOI: 10.1038/nature14011

11 Suzuki K, Watanabe S, Wakabayashi M, Moriya Y, Yoshino I, Tsuboi M, Mitsudomi T and Asamura H: A nonrandomized confirmatory phase III study of sublobar surgical resection for peripheral ground glass opacity dominant lung cancer defined with thoracic thin-section computed tomography (JCOG0804/WJOG4507L). J Clin Oncol 35: 8561-8561, 2017. DOI: $10.1200 /$ JCO.2017.35.15_suppl.8561

12 Yatabe Y, Borczuk AC and Powell CA: Do all lung adenocarcinomas follow a stepwise progression? Lung Cancer 74: 7-11, 2011. PMID: 21705107. DOI: 10.1016/j.lungcan.2011.05.021

Received March 11, 2019

Revised April 25, 2019

Accepted April 25, 2019 